\title{
European mink: restoration attempts for a species on the brink of extinction
}

Tiit Maran, Madis Põdra, Lauren A. Harrington, and David W. Macdonald

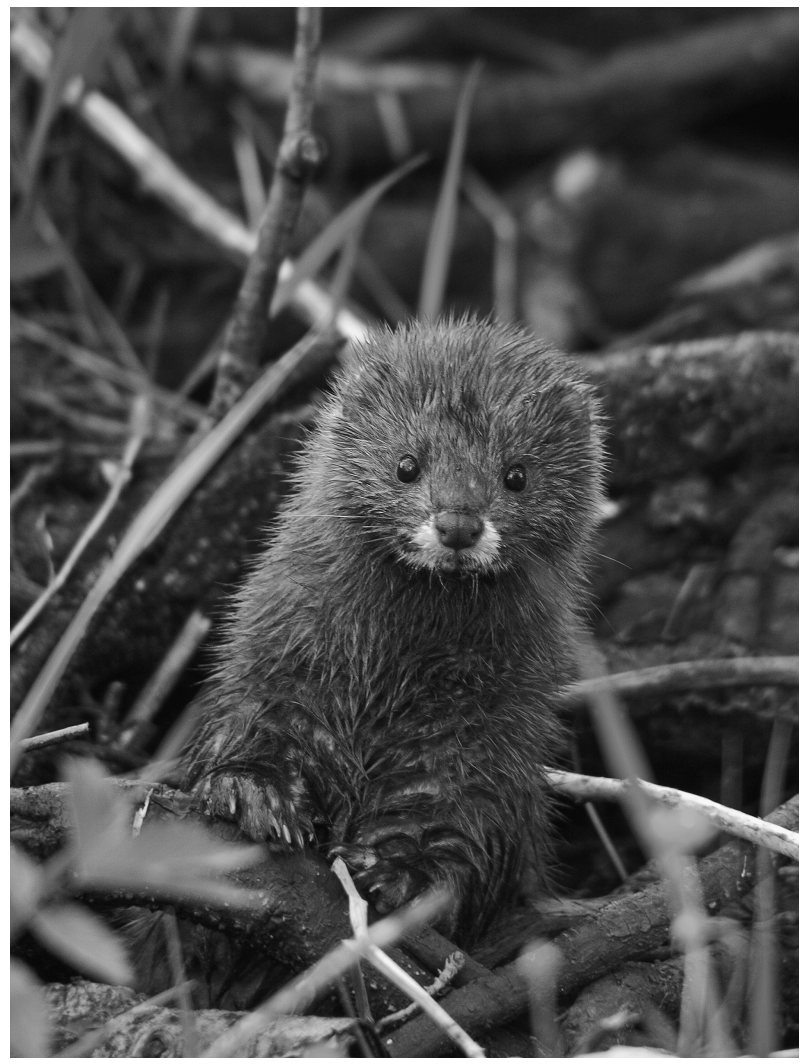

European mink (C) Tiit Maran

\section{Decline of the European mink}

The European mink (Mustela lutreola) was once widespread throughout Europe, with a range that extended from the Ural mountains to eastern Spain and from Finland to the Black Sea (Novikov 1939; Heptner et al. 1967, Figure 17.1). Since the nineteenth century, however, its range has dwindled drastically (reviewed in Maran et al. 1998a and in Maran 2007) such that it is now in danger of becoming the next mammalian extinction. There is no known large population of European mink surviving in the wild; their decline is continuing, and the species retains only isolated fragments of its former range in small areas of southwestern 


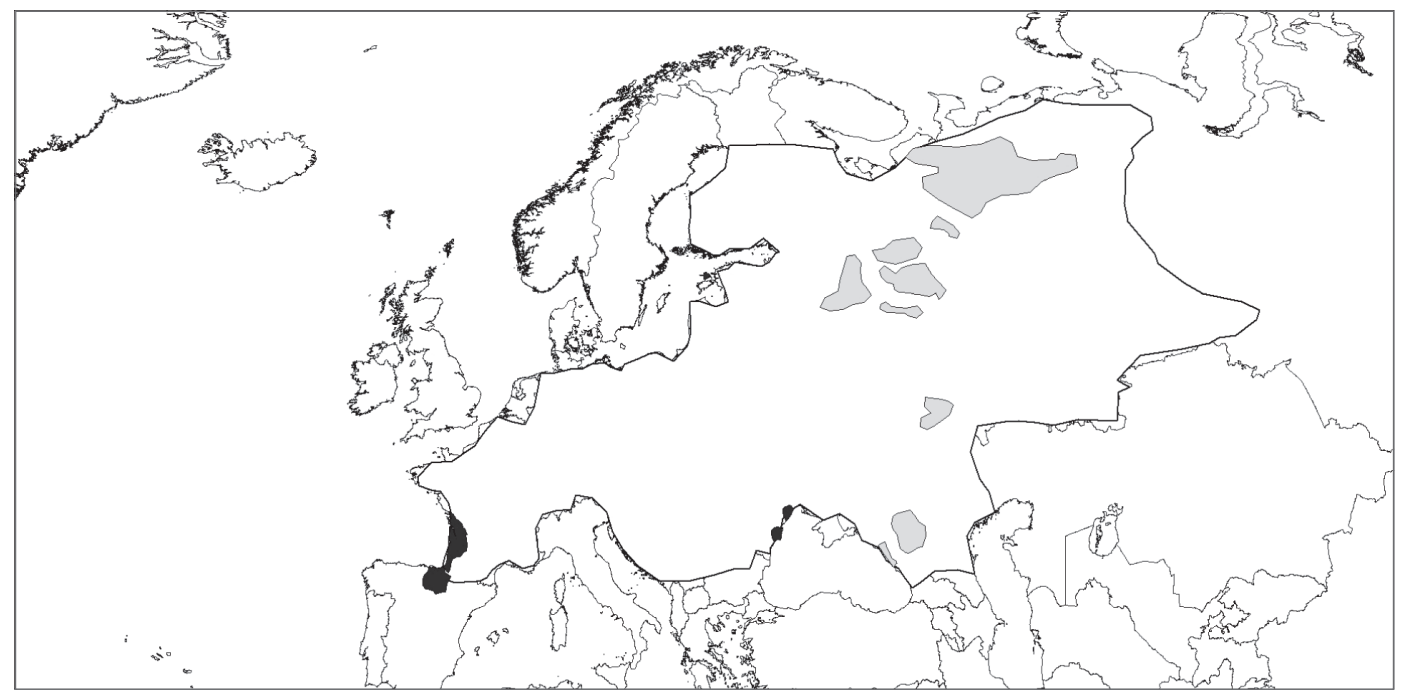

Figure 17.1 Historical (white) and estimated current (grey) range of European mink. The presence of the European mink in Spain, France, Romania, and Ukraine (shown in dark grey) is based on field data, whereas the information from Russia (in light grey) is based on questionnaires and local knowledge (Dr. D. Skumatov, pers. comm. 2012). The population in the Danube delta is widespread but of unknown size. The small reintroduced 'population' on the Estonian island of Hiiumaa, and reintroduction sites in Germany, are not shown; European mink were last confirmed in mainland Estonia in 1996, and disappeared from Germany in the nineteenth century.

France and northeastern Spain, the Danube delta (in Romania and Ukraine), and probably restricted parts of Russia, as well as a small reintroduced population in Germany (Maran et al. 2016b, Figure 17.1). Indeed, our former study population in northeastern Belarus is now believed to be extinct (Sidorovich 2011).

In this chapter, we review restoration efforts undertaken over the past 17 years in Estonia and Spain in an attempt to save this species from extinction. First, we outline the ecology of the species, the reasons for the decline, and discuss the role of the invasive American mink (Neovison vison) (an introducee of the fur trade, see Macdonald et al., Chapter 1, this volume).

At less than $1 \mathrm{~kg}$, the European mink is one of the smallest European carnivores. It is solitary and, across most of its range, occurs in sympatry with the European polecat (M. putorius), Eurasian otter (Lutra lutra), pine marten (Martes martes), stone marten (Martes foina), stoat (M. erminea), and weasel (M. nivalis), and (in France and Spain) the common genet (Genetta genetta) (all of which, with the exception of stoats and weasels, are larger than the European mink). European mink are occasionally killed by lynx ( $\operatorname{Lnn} x \operatorname{lynx})$, red foxes (Vulpes vulpes), raptors and large owls, and domestic dogs. They tend to be crepuscular and usually found within $100 \mathrm{~m}$ of the water (e.g. Zubergoitia and Zabala
2003), where males and females may occupy home ranges of up to 17 and $10 \mathrm{~km}$ along rivers and streams, respectively (averages in France and Spain for males were 11-13 km [see, for example, Garin et al. 2002], but elsewhere, dependent on habitat, they may be much smaller: e.g. $2.4 \mathrm{~km}$ in Russia, Danilov and Tumanov 1976). European mink are generalist predators, taking both aquatic and terrestrial prey items.

Three main factors have contributed to the decline of the European mink-habitat loss/degradation, over-exploitation and the effects of the alien American mink - and detailed assessment of the sequence of events, backed up by over two decades of research, has revealed that the particular set of factors and their relative importance in the decline of this species has differed over time and among regions (summarized in Maran and Henttonen 1995; Maran et al. 2016b). The course of decline during the twentieth century in the central regions of Russia provides a good illustration. There, the effect of over-exploitation in the early decades of the century (annual harvests of 40,000 to 75,000 across the former Soviet Union) was such that a temporary moratorium was placed on hunting European mink in several regions, and 130 European mink were translocated in an attempt to reinforce the depleted population in the Yaroslav Region, in Central Russia 
(northeast of Moscow, Novikov 1939). Extensive habitat alteration associated with agriculture and forestry in the mid-twentieth century further contributed to the decline; thereafter, the invasion of the American mink delivered the coup de grace. Elsewhere in Europe, American mink invaded as escapees from fur farms established in the 1920s and 30s, but in Russia their invasion was facilitated by the release of over 20,000 individuals into the wild to bolster declining fur harvests. At the time, American and European mink were considered, by the relevant authorities, to be the same species (see Macdonald et al., Chapter 1, this volume), European mink were too scarce to support the fur trapping industry, and, in any case, the fur of the American mink commanded a higher price (Pavlov and Korsakova 1973). Much like the introduction of stoats and weasels into New Zealand (King et al., Chapter 10, this volume), the introduction of American mink to Russia seemed logical at the time. The original intention was to release American mink in regions outside the European mink's range, but 4000 of the 20,000 were released within the range of the European mink (Pavlov and Korsakova 1973). Escapees from fur farms through the second half of the twentieth century formed a continuous source of new immigrants that, being ecologically more flexible and competitively superior (Maran 1991; Maran and Henttonen 1995; Maran et al. 1998b), were able to invade the largely empty niche of the already much reduced and fragmented European mink population, thus making it impossible for the depleted European mink to recover.

The early disappearance of European mink in central Europe (Germany, Switzerland, and Austria) in the nineteenth century was probably due to large-scale habitat destruction due to wetland drainage and channelling of rivers for agricultural purposes (Maran and Henttonen 1995); likewise, the more recent disappearance of the European mink from northern and western France (and the loss of half of the former French range) between the late 1970s and early 1990s is attributed largely to contemporary anthropic pressures on natural habitats (e.g. pollution and accidental capture in traps set for European polecats, Lodé et al. 2001, see also Maizeret et al. 2002). In Finland, the initial cause of the decline between the 1920s and the 1950s is unclear (perhaps associated with hunting in the 1920s) but Maran and Hentonnen (1995) suggest that recovery following legal protection was prevented by the high density of American mink there. In all cases, a number of factors (including, in addition, potential competition and hybridization with European polecats, Macdonald et al. 2002c; Lodé et al. 2005) have probably had a synergistic effect on the
European mink. The role of the alien American mink has, nevertheless, been (and continues to be) key.

\section{The role of the American mink}

In Estonia, the Tver Region in Central Russia (north of Moscow), parts of the Basque country in northern Spain, and in Belarus (Maran et al. 2016b and references therein) local extinction of the European mink coincided with the rapid expansion of the American mink. On the Lovat River in northeastern Belarus, monitoring of European mink density between 1986 and 1998, covering both before and after the arrival of American mink in 1988, provided circumstantial evidence incriminating the American mink: prior to the arrival of the American mink, European mink densities on small rivers were about seven individuals per $10 \mathrm{~km}$, but fell rapidly to less than two per 10 $\mathrm{km}$ three years after (Sidorovich and Macdonald 2001, Figure 17.2). Subsequently, our work in this region with Vadim Sidorovich showed that larger American mink (body mass, mean \pm SE: male: $1310.2 \pm 38.9 \mathrm{~g}$, $\mathrm{n}=42$; female: $780.7 \pm 21.0 \mathrm{~g}, \mathrm{n}=23$ ) outcompete the smaller European mink (male: $976.6 \pm 24.5 \mathrm{~g}$, $\mathrm{n}=14$; female $667.0 \pm 12.7 \mathrm{~g}, \mathrm{n}=8$, Sidorovich et al. 1999) by direct interspecific aggression. Despite similarities in appearance and ecology, the two species are not closely related (see Macdonald et al., Chapter 1, this volume). Both use semi-aquatic habitats but American mink appear to be more adaptable and use both the river habitat and the surrounding wetlands where they inhabit lakes, pools, marshes, and old river beds up to $2 \mathrm{~km}$ from the nearest riverbank or shore, whereas European mink stay closer to densely vegetated banks and shores of small rivers, streams, and lakes (Sidorovich and Macdonald 2001). Similarly, both consume a wide variety of small mammals, amphibians, fish, crayfish, and birds (dependent on season, local availability, and individual preference, Maran et al. 1998b; Sidorovich et al. 1998, 2001; Sidorovich 2000; Palazón et al. 2004, 2008); interspecific differences are sometimes reported at a local scale but these are most likely due to local differences in habitat use (Maran et al. 1998b). In Belarus, the food niche of the European mink narrowed (to include mainly frogs, with little aquatic prey) during the course of the invasion by American mink, while that of American mink widened (with a notable increase in aquatic prey, Sidorovich et al. 2010), presumably due to progressive exclusion of European mink from preferred habitats. American mink populations can produce litters that are significantly larger than those 


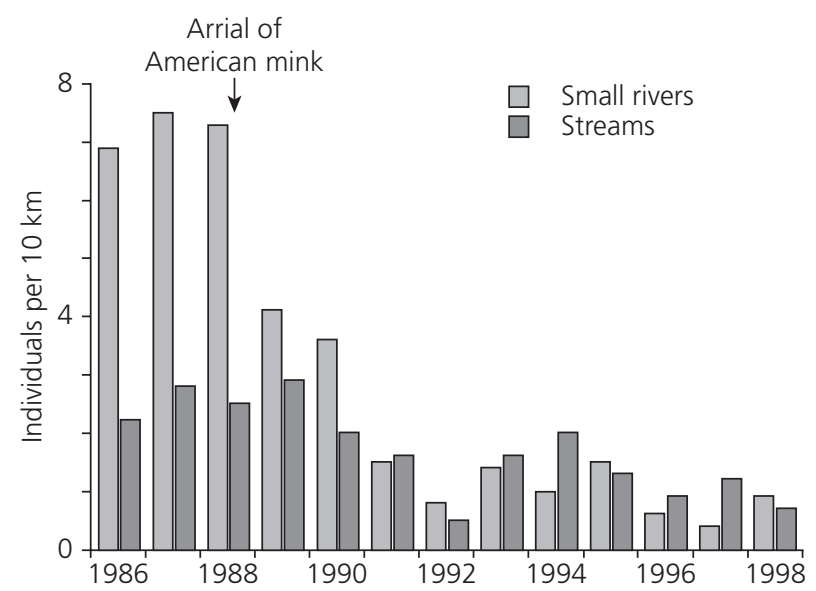

Figure 17.2 European mink density on the upper reaches of the Lovat River, Belarus, in winter (1986-1998) in small rivers (light grey) and streams (dark grey). Rivers are 5-25 m wide and $0.5-2.5 \mathrm{~m}$ deep (and may be slow- or fast-flowing). Streams are $0.5-2 \mathrm{~m}$ wide and 0.1-0.8 $\mathrm{m}$ deep, and are often dry in the summer. The first American mink was trapped in the study area in December 1988; by spring 1990 it was common. Reproduced from Macdonald and Harrington (2003), and Sidorovich and Macdonald (2001). of European mink populations (e.g. for litters aged $>$ 1 month in Belarus, mean $=5.8$ versus 2.4, Sidorovich 1993; and in France/Spain, mean $=7.5$ versus 3.4, Fournier-Chambrillon et al. 2010) and thus presumably have the capacity to quickly outnumber their European competitor. Certainly, within four years of their arrival in the Lovat valley, American mink occupied all aquatic habitats at a higher density than European mink (Sidorovich and Macdonald 2001).

Initially, in Belarus European mink appeared to persist (albeit at low densities, Figure 17.2) in sub-optimal stream habitats used less frequently by American mink, but sex ratios were increasingly male-biased (before the arrival of the American mink: 1.2:1; after: 5.1:1) because these habitats were rarely used by female European mink (perhaps because resources were insufficient for females to raise kits there, Sidorovich 2000). During our Belarussian field study, 33 litters were found along small rivers and glacial lakes; none was ever found at small streams (Sidorovich 2000; Sidorovich and Macdonald 2001). Over five years of radio-tracking, aggressive encounters were recorded in 14 of 16 cases where American and European mink came within $200 \mathrm{~m}$ of one another, and 13 of these 14 encounters were initiated by male American mink (directed towards European mink of both sexes) (Sidorovich et al. 2000). Following such encounters European mink fled, usually into unsuitable habitats, before attempting to return 1-22 hours later. Further behavioural observations in captivity also demonstrated that American mink of both sexes were more aggressive to European mink than vice versa (Maran et al. 1998a). At a population level, European mink of both sexes increased significantly in both body size and body weight following the arrival of the American mink, which Sidorovich et al. (1999) suggest may be the result of reduced survivorship of smaller individuals (as a result of aggression from American mink). Similar increases in European mink body size have been recorded in Western Russia (Macdonald et al. 2002c).

In short, after 12 years of studying the European mink and interactions among the guild of mustelids (native and non-native) occupying the remote Lovat river valley, the outcome was that the American mink aggressively ousted the European mink from the slow-flowing small rivers first, as that is its preferred habitat, and finally occupied all areas (reviewed in Macdonald and Harrington 2003). European mink have not been seen in the Lovat river valley since 2003 (V. Sidorovich, pers. comm.). There are no records of long-term coexistence of these two mink species, and, whilst there are numerous accounts of local replacement of the European mink with the American mink, there is none in which the opposite has occurred (Maran et al. 2016b).

American mink are now largely contiguous across Russia to the Far East (Khlyap et al. 2011, D. Skumatov, pers. comm.) and probably occupy all of the remaining range of the European mink except perhaps parts of the Danube delta (de Jongh et al. 2007; Maran et al. 2016b), North Caucasus (in southern Russia), and the extreme northwest of the European mink's Russian range (which is close to the northern limit of the European mink's range and where European mink are naturally relatively rare).

For now, European mink persist in northeastern Spain, helped by intensive American mink control 
there over the last decade. Nevertheless, even in Spain, European mink are in trouble, American mink are abundant, and the fur farming industry there is thriving. Although several countries in Europe have recently banned fur farms (see Fraser et al., Chapter 16, this volume), and new mink farms are not permitted within the area of Spain occupied by European mink, they remain legal in some other regions in Spain, and increasing fur prices (due largely to an increase in demand from China but also renewed fashion interest in fur, see Harrington et al., Chapter 7, this volume) have led to increasing investment in the Spanish fur trade. In recent years several new mink farms have been opened in Galicia (where the climate is ideal for breeding mink, see map in Figure 17.9a); as of 2015, 54 mink farms were in operation in Spain (including two existing farms that remain in the Basque country, within the range of European mink, MAGRAMA 2014) with an annual production of about 800,000 mink pelts (Fur Europe 2015, www.fureurope.eu). To judge by history, escapes from farms seem almost inevitable. European mink distribution in the north of Spain is fragmented and European mink are disappearing from rivers where American mink are caught (Palazón et al. 2002; Zuberogoitia et al. 2013). Interestingly, concomitant with their decline in the north of Spain, European mink appear to have undergone an expansion of their Spanish range to the south and south-east. In fact, they appear to have been slowly but steadily increasing their range southwards since they were first observed in Spain in the 1950s (Gómez et al. 2011). We discuss both of these points, and describe our work in Spain, further below. First, we give a brief overview of the beginnings of captive breeding efforts to produce animals for release, focussing on two particular issues-male mating failure and preparing ('pre-conditioning' or 'training') captive-bred animals for life in the wild.

\section{Captive breeding}

The apparently imminent threat of extinction of the European mink, and the anticipated goal of providing animals for release into the wild in the future, made urgent the need for a captive breeding programme, which was initiated by one of us (TM) at Tallinn zoo, Estonia, in 1984. The first breeding success occurred in 1986, with three of the six females in captivity producing litters, and in 1992 a formal European mink breeding programme was established under the EAZA's (European Association of Zoos and Aquaria)
European Endangered species Programme (EEP), coordinated by Tallinn zoo and the Foundation Lutreola (www.lutreola.eu). Nine countries now participate in the programme: Estonia, the Czech Republic, Finland, France, Germany, Latvia, the Netherlands, Poland, and the Slovak Republic.

As of December 2016, there were 210 European mink (115 of which were males) in captivity under the EEP program, half of which are held at Tallinn zoo, and all of which come from 22 founders (predominantly from northeast and central Russia). By comparison, the entire black-footed ferret (Mustela nigripes) population is based on only seven founders (see Biggins and Ead, Chapter 15, this volume). Mating is usually successful when it takes place (on average, $76 \%$ of mated females and $80 \%$ of mated males between 1996 and 2015 produced or sired young), and litter size is high (mean $=4$, Table 17.1), but male

Table 17.1 European mink reproduction at Tallinn zoo.

\begin{tabular}{lrrrrrr}
\hline Year & $\begin{array}{l}\text { No. } \\
\text { young }\end{array}$ & $\begin{array}{l}\text { No. } \\
\text { litters }\end{array}$ & $\begin{array}{c}\text { Average } \\
\text { litter size }\end{array}$ & \multicolumn{2}{c}{$\begin{array}{l}\text { \% mated individuals } \\
\text { resulting in a litter }\end{array}$} \\
\cline { 5 - 7 } & & & & Average & Females & Males \\
\hline 2015 & 54 & 12 & 4.5 & 76.7 & 76.5 & 76.92 \\
2014 & 73 & 14 & 5.2 & 75.7 & 76.5 & 75 \\
2013 & 44 & 11 & 4 & 63.0 & 68.8 & 57.14 \\
2012 & 59 & 15 & 3.9 & 78.6 & 77.3 & 80 \\
2011 & 21 & 6 & 3.5 & 58.0 & 50.0 & 66 \\
2010 & 46 & 10 & 4.6 & 44.5 & 59.0 & 30 \\
2009 & 53 & 12 & 4.4 & 89.3 & 78.5 & 100 \\
2008 & 124 & 22 & 5.6 & 92.9 & 91.7 & 94.12 \\
2007 & 84 & 18 & 4.6 & 86.0 & 86.0 & 86 \\
2006 & 80 & 15 & 5.3 & 72.0 & 73.0 & 71 \\
2005 & 83 & 18 & 4.6 & 89.2 & 86.0 & 92.31 \\
2004 & 94 & 20 & 4.7 & 90.8 & 95.0 & 86.66 \\
2003 & 57 & 14 & 4.1 & 72.5 & 70.0 & 75 \\
2002 & 62 & 14 & 4.4 & 80.5 & 78.0 & 83 \\
2001 & 53 & 14 & 3.8 & 74.5 & 74.0 & 75 \\
2000 & 72 & 18 & 4 & 93.0 & 86.0 & 100 \\
1999 & 32 & 10 & 3.2 & 85.5 & 71.0 & 100 \\
1998 & 66 & 14 & 4.7 & 91.0 & 82.0 & 100 \\
1997 & 22 & 6 & 3.7 & 70.0 & 67.0 & 67.0 \\
\hline 1996 & 6 & 1 & 6 & 100 & 100 & 100 \\
\hline Average & $1996-2015$ & 4 & 78.32 & 75.83 & 80.08 \\
\hline
\end{tabular}


mating failure is an ongoing problem. For example, in 2009 and 2010 only 40 and 43\%, respectively, of males paired with females copulated (Kiik et al. 2013; see also Amstislavsky et al. 2008). Comparisons of mating success between wild- and captive-born individuals (during years when the captive population at Tallinn zoo still consisted of some wild-born animals) revealed that mating failures were primarily attributable to the captive origin of the animal rather than the immediate environmental conditions during breeding attempts: of 20 wild-born males, 13 (65\%) successfully bred at least once in their time in captivity, whereas of 201 captive-born males, only 23 (11\%) successfully bred at least once in their lifetime. No such association between mating success and origin was found for females. Detailed analysis of captivebred male behaviour during pairing showed that most mating attempts failed due to lack of interest in the female $(47 \%)$ or aggression towards the female (24\%) — which Kiik et al. (2013) refered to as two alternative expressions of a general behavioural inability to mate. What precisely causes these abnormal mating behaviours is not clear, but it may be associated with social stress (as has been suggested for captive wolverines [Gulo gulo], Dalerum et al. 2006, and black-footed ferrets, Wolf et al. 2000).

For reintroduction, it is important that captive breeding programmes provide an environment that allows young captive-born animals to acquire survival skills necessary for life in the wild. Mink raised in enclosures without pools, for example, are reluctant to swim later in life (Macdonald et al. 2002). European mink in Tallinn zoo are kept in small $(2 \times 4 \mathrm{~m})$ standard zoo cages or larger $\left(25-200 \mathrm{~m}^{2}\right)$ 'naturalistic' enclosures (all with pools, Figure 17.3), and, more recently, pregnant females have been transferred to on-site enclosures (a)

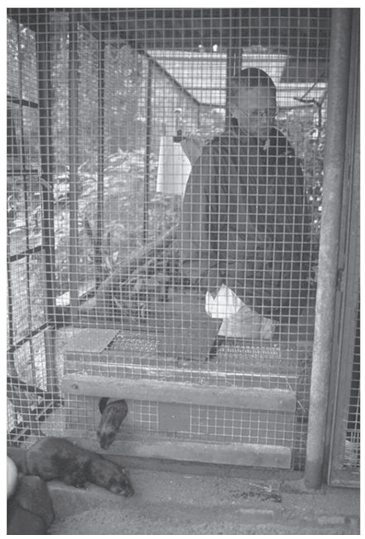

(b)

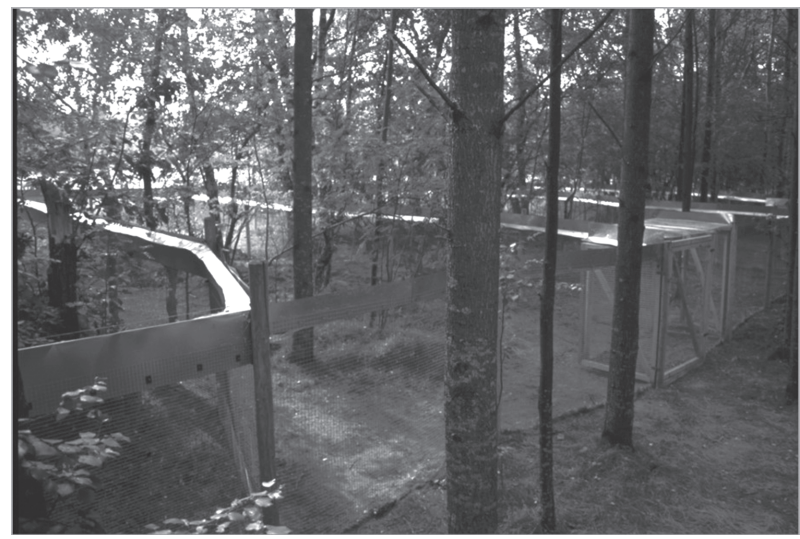

(c)

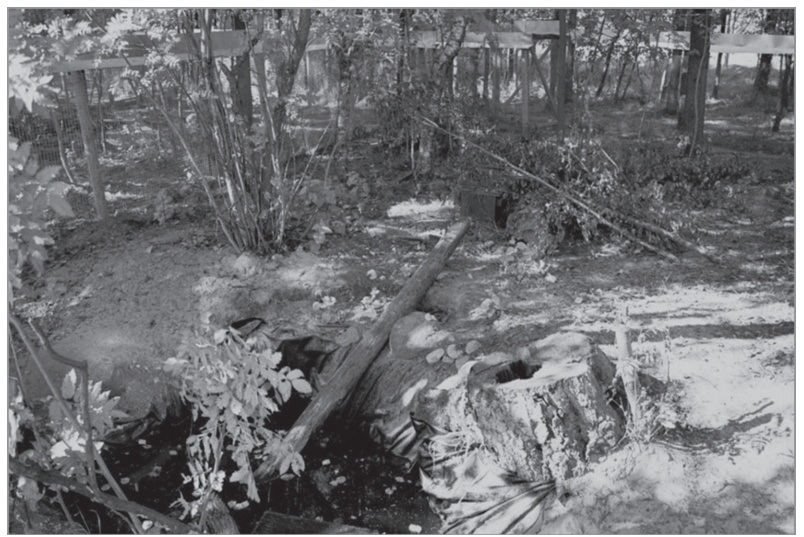

Figure 17.3 Captive breeding facility in the Species Conservation Research Lab at Tallinn Zoo. a) European mink in a standard zoo cage (cages are now constructed with plywood barriers to separate the animals from their keepers and other humans), b) 'naturalistic' enclosures, and c) features inside a naturalistic enclosure. (c) (a) A.L. Harrington, (b, c) T. Maran. 
prior to release. Initially, attempts were also made to train mink to avoid predators and to catch prey; the former is fraught with practical difficulties (and was abandoned), the latter is easier in practical terms, but fraught with ethical dilemmas. Observations of captive-bred and wild-caught mink revealed that captivebred individuals took longer and made more dives to catch their first fish, were slower to capture and kill a crayfish, and to find and break open a partridge egg, but that they quickly became more proficient at capturing and handling prey if given experience (Macdonald et al. 2002). Thus, whilst there are of course ethical issues in feeding live prey (and the practice is in any case illegal in some other countries, including the UK), one might also argue that it would be morally wrong to release an ill-prepared individual into the wild. In this case, the ethical concerns for the prey were considered to be outweighed by the importance of ensuring that this highly endangered animal would be able to obtain food in the wild. These types of ethical dilemmas are common in reintroductions (reviewed in L. Harrington et al. 2013) and there is considerable debate within the conservation community as to what is the 'right' approach to take (see e.g. Waples and Stagoll 1997; Bekoff 2010; Reading et al. 2013). In general, we suspect that raising animals in large natural enclosures ('pre-conditioning') is more effective, in terms of animals learning survival skills, than 'training' per se. Nevertheless, mink are still given the opportunity to kill live prey and on-site enclosures are occasionally provisioned with live fish and frogs; the effectiveness and the necessity of these methods need to be tested.

\section{Creation of an island sanctuary}

Arguably one of the most important decisions in restoring populations of any endangered species is where they should be released. In the case of European mink, the key criterion for a suitable site (in addition to the availability of sufficient suitable habitat), was the absence of its American counterpart. Given the widespread distribution of the American mink, the only realistic option at the time was deemed to be an area from which American mink could be removed and that could subsequently be protected from re-invasion: in short, an island. The idea of island sanctuaries is not new and there is a long history of releasing endemic New Zealand birds to islands free of non-native mustelids (reviewed in Jones and Merton 2012). The Estonian island of Hiiumaa was selected on the basis of habitat suitability, feasibility of removing American mink, low probability of re-invasion by American mink, relatively low human population density, and proximity to ongoing captive breeding efforts in Estonia.

Hiiumaa island is in the Baltic Sea, $22 \mathrm{~km}$ from the Estonian mainland (and thus beyond the distance reachable by American mink by sea), and forms part of the West-Estonian Archipelago Biosphere reserve (part of the UNESCO's Biosphere Reserve Network). The island (and associated islets) has an area of about $1000 \mathrm{~km}^{2}$, approximately $60 \%$ of which is coniferous and deciduous forest intersected by an extensive network of $326 \mathrm{~km}$ of rivers and $c .100 \mathrm{~km}$ of man-made drainage canals, and 13 lakes, as well as marshes and bogs (Figure 17.4). There were a number of potential competitors on the island-including pine martens, otters, racoon dogs (Nyctereutes procyonoides), red foxes, and various raptor species-but also plentiful prey, including water voles (Arvicola amphibius, formerly A. terrestris), eight species of small rodents, five species of amphibians, reptiles, several fish species, and crayfish (Astacus astacus, details in Maran et al. 2009). The island is estimated to be able to support an over-wintering population of 88-109 European mink (Maran and Põdra 2013).

Only 53 American mink were captured over two years of trapping (1998 and 1999) but the island was declared mink-free when an intensive 21-day snowtracking survey in February-March 2000 failed to detect any mink tracks (Macdonald et al. 2002). In June 2000, the first nine European mink were released on the island, having been transported $150 \mathrm{~km}$ from Tallinn zoo, and, between 2000 and 2003 (in May and June each year, and juveniles in September), a total of 172 captive-bred European mink (including juveniles approximately 3 months old - the age of natural dispersal, yearlings, and adults, some pregnant females, all of variable generations in captivity, raised in either standard zoo cages or large naturalistic enclosures) were released in the first of three phases of reintroduction efforts (Table 17.2). All individuals were immediately released on arrival at a suitable site on the island on the riverbank of small rivers or canals. No support was provided in the way of food or shelter (i.e. a 'hard' release) but we monitored the animals' diet (via analysis of collected scats, Põdra et al. 2013a), and the movements (Harrington et al. 2014) of a subset of animals $(n=54)$ that were equipped with radio-collars (details in Maran et al. 2009) to assess how they were adapting to the wild.

Whilst there are often constraints due to the availability of animals for release in these types of projects (which hinders experimental design), there are also 


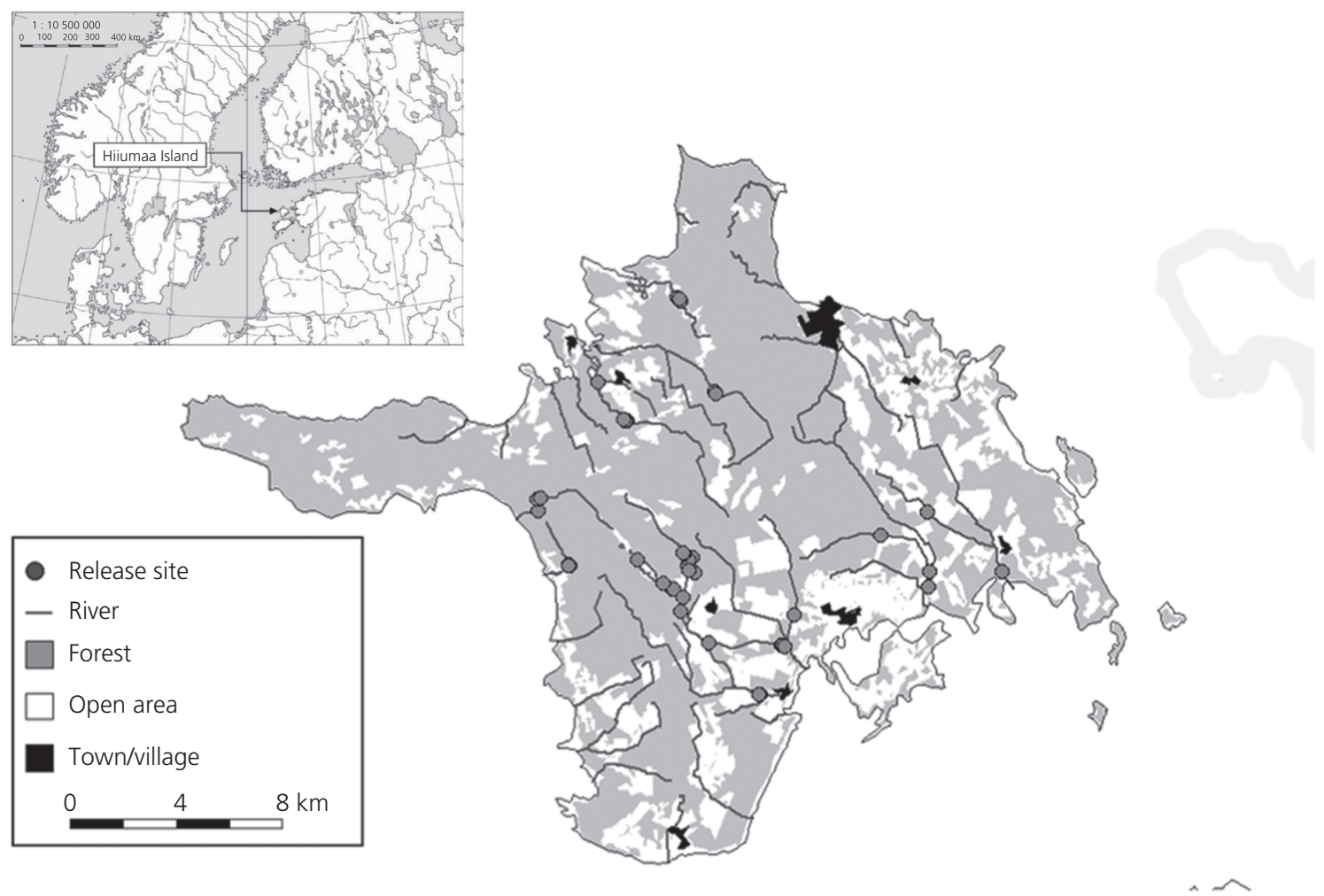

Figure 17.4 Hiiumaa Island, Estonia, and initial European mink release sites in 2000-2002. Inset shows the location of Hiiumaa Island in the Baltic Sea. Reproduced from Harrington et al. (2014).

opportunities for experimentation. With this in mind, we aimed to learn as much as possible during the first phase of reintroduction with a view to adapting and improving our methods in future years. Three important questions were:

1) Are there particular demographic factors that might contribute to success (i.e. are younger or older animals better suited to survival, and, could pregnant females be released to give new 'wild-born' young a head-start)?

2) Does the number of generations in captivity affect an animal's chances of survival in the wild?

3) Could an individual's probability of survival be increased by prior experience in captivity (i.e. by exposure to more naturalistic conditions and reduced human contact)?

Evidence of the latter is provided by the extensive research carried out on the reintroduction of the black-footed ferret, in which researchers found that survival of black-footed ferrets raised in natural arenas at one month post-release was almost three times higher than that of ferrets raised in standard zoo cages (and 10 times higher at 9 months postrelease, Biggins et al. 1998; see Biggins and Eads, Chapter 15, this volume). For European mink on Hiiumaa, there was no detectable difference in survival between yearling and adult mink (Maran et al. 2009) but juveniles moved further from the release site, moved more erratically, and ranged over larger areas than did yearlings and adults (Harrington et al. 2014). Pregnant mothers appeared to fare well, with no detectable difference in survival between pregnant and non-pregnant females, but their kits did not. Of eight pregnant females released, the litters of three were observed, and all disappeared at 1.5-2 months of age. There was no evidence of increasing generations in captivity reducing the probability of survival, and Maran et al. (2009) concluded that it is likely that pre-release factors that shape the behavioural capacity of mink after release matter more. There was some evidence that animals (particularly 
Table 17.2 European mink released on Hiiumaa Island, 2000-2015. During Phase 1, animals were transported from Tallinn zoo (where they had been raised in standard zoo cages or larger, naturalistic enclosures) and released immediately on the island without provision of food or shelter ('hard' release). During Phase 2, animals from naturalistic zoo enclosures (no standard zoo cages were used in Phase 2) were hard released as in Phase 1; animals born in on-site enclosures on the island were 'soft' released by opening the doors of the enclosure so that they could leave when they chose, and were able to return to the enclosure for food or shelter. Phase 3 was a continuation of Phase 2 but included new monitoring techniques and comparisons of survival for animals of different personality type. See text for details.

\begin{tabular}{|c|c|c|c|c|c|}
\hline Year & $\begin{array}{l}\text { Total no. } \\
\text { mink } \\
\text { released }\end{array}$ & $\begin{array}{l}\text { No. } \\
\text { pregnant } \\
\text { females }\end{array}$ & $\begin{array}{l}\text { No. } \\
\text { released } \\
\text { from } \\
\text { on-site } \\
\text { enclosures }\end{array}$ & Phase & $\begin{array}{l}\text { No. } \\
\text { radio- } \\
\text { tracked }\end{array}$ \\
\hline 2000 & 17 & & & 1 & 17 \\
\hline 2001 & 41 & & & 1 & 18 \\
\hline 2002 & 54 & 12 & & 1 & 12 \\
\hline 2003 & 60 & 14 & & 1 & 14 \\
\hline 2004 & 35 & 7 & 13 & 2 & 10 \\
\hline 2005 & 50 & & 16 & 2 & \\
\hline 2006 & 39 & & 13 & 2 & \\
\hline 2007 & 30 & & 14 & 2 & \\
\hline 2008 & 70 & & 20 & 2 & \\
\hline 2009 & 40 & & 19 & 2 & \\
\hline 2010 & 12 & & 10 & 2 & \\
\hline 2011 & 7 & & 7 & 2 & \\
\hline 2012 & 21 & & 15 & 2 & \\
\hline 2013 & 15 & & & 3 & 15 \\
\hline 2014 & 44 & & 20 & 3 & 4 \\
\hline 2015 & 30 & & 15 & 3 & \\
\hline
\end{tabular}

females) raised in large naturalistic enclosures with minimal human contact survived better than did animals raised in standard zoo cages, but the effect was not statistically significant (probably because of small sample size and natural variation among individuals, Maran et al. 2009).

Of the 52 radio-tracked animals released between 2000 and 2002, 15 (27\%) survived and were monitored for a month or more; by the end of August 2002, 21 animals $(40 \%)$ were confirmed dead, $25(48 \%)$ were lost (due to collar or signal loss), and $6(12 \%)$ were known to be alive (Harrington et al. 2014). Of 22 known deaths (recorded over the first three months post-release in
2000-2003), 68\% occurred within the first two weeks (Harrington et al. 2014; Maran et al. 2009). The main cause of death was predation (75\% of recorded deaths, Figure 17.5) by other carnivores (mostly red fox, domestic dog) and raptors (probably goshawks [Accipiter gentilis], or Ural owls [Strix uralensis]). Overall, estimated survival rates (taking account of animals lost to monitoring) were significantly higher for males than for females (with one month post-release survival, for a subset of 28 individuals, all released from standard zoo cages, being $74 \%$ for males but only $25 \%$ for females). These high mortality rates in the first few weeks postrelease are typical of reintroductions of captive-bred animals (e.g. Jule et al. 2008) but nevertheless suggest that methods could be improved.

Analysis of 564 scats showed that released individuals were successfully finding and catching prey, but for the first 10 days post-release they appeared to survive on atypical prey such as birds, insects, and snails, as well as occasional domestic chickens, rabbits, and kittens (Põdra et al. 2013a). Within 30 days, diet became more typical of wild European mink elsewhere-comprising predominantly crayfish, fish, and small mammals. Maran et al. (2009) and Põdra et al. (2013a) suggest that released captive-bred mink undergo a natural adaptation period of between four and six weeks after release. Defining that adaptation period and pinpointing exactly what it is that makes released animals vulnerable during this period is difficult, however. The proximate cause of death for most released mink - predation - may arise from a number of interrelated ultimate factors, such as the weakening of animals due to the inability to find food (or to find the 'right' food), straying from their natural habitats (Põdra et al. 2013a), making excessive movements, or simply being active for too long (Harrington et al. 2014) —all of which may render animals susceptible to predation (e.g. Miller et al. 1994).

By the end of the first phase, there was little robust scientific evidence of the benefits of large, naturalistic enclosures, but ongoing observations by TM of animals in captivity suggested that the behaviour of individuals raised in standard zoo cages was not suitable for life in the wild. Since it is also important to release animals as young as possible (to allow maximum breeding opportunities for those that successfully establish in the wild), but kits born to females released when they were pregnant seemed not to survive, and hard-released juveniles released at 3 months old behaved erratically, another method of providing captive-bred individuals with appropriate pre-release 

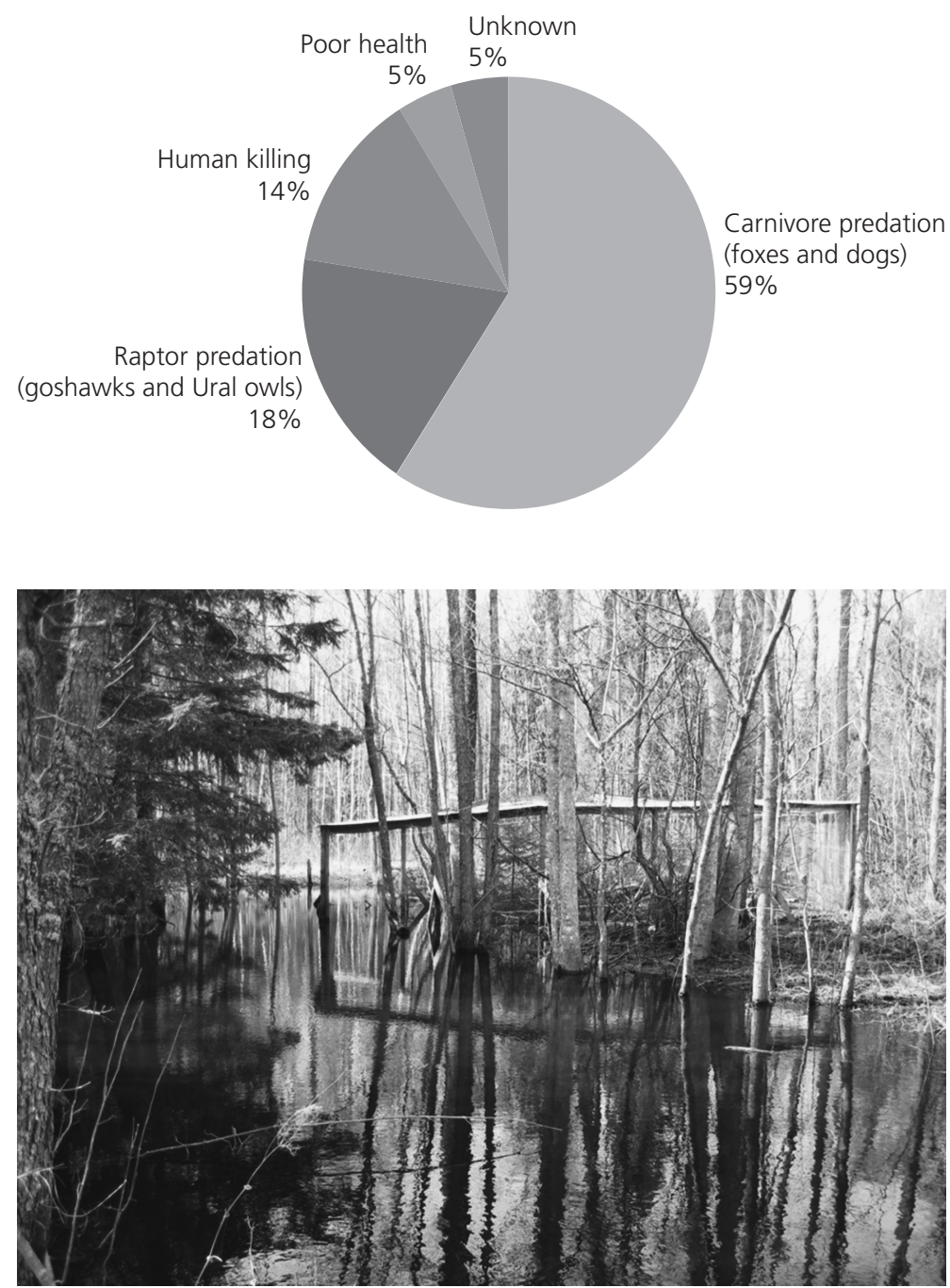

Figure 17.5 Causes of death for captivebred mink released on Hiiumaa island, Estonia, 2000-2003 ( $n=22$ known deaths). Reproduced from Maran et al. (2009).
Figure 17.6 On-site pre-release enclosure on Hiiumaa island, Estonia. (C) Tiit Maran. experience but also releasing them at a very young age was needed.

Since 2004 (second phase of reintroduction efforts), young mink destined for release have been born either in on-site enclosures (Figure 17.6) or in naturalistic enclosures (minimum $100 \mathrm{~m}^{2}$ ) at Tallinn $\mathrm{zoo}$, and are released at the natural dispersal age (two to three months old) with the rest of their litter and (for onsite enclosures) with their mothers. Pregnant females are transferred to the enclosures (either on-site or zoo enclosures) during the second or third week of pregnancy. On-site enclosures are provisioned with food (dead mice and minced meat, and occasionally live prey), and animals released by opening the doors at two to three months. Food provision is continued for two to three weeks after release, but the animals usually abandon the enclosures within two weeks. Animals raised in zoo enclosures are transported to Hiiumaa and released immediately as in Phase 1. It has not been possible to test formally the relative success of on- or off-site release approaches, but there is considerable evidence from other species suggesting that early exposure to (i.e. being born in) suitable natural habitats is crucial for later development of appropriate habitat preferences (e.g. Davis and Stamps 2004; Stamps and Swaisgood 2007).

Between 2004 and 2015, a further 390 mink were released on Hiiumaa (Table 17.2), and the status of 
mink on the island monitored annually using snow track surveys in winter, followed by live-trapping in spring and sign surveys in summer (Figure 17.7a). Since 2014, camera traps have also been used for additional information and particularly to gain information on litter size (Figure 17.7b). In 2013 and 2014 (Phase 3), a subset of animals was also radio-tracked as part of a separate study (which we discuss below) to assess the potential link between 'personality' type and post-release survival. Prey (predominantly amphibian) availability was also monitored and habitat improvement (construction of artificial ponds, Remm et al. 2015, Figure 17.8) was carried out where necessary. As of 2016, 65 mink are estimated to be present on Hiiumaa Island, $75 \%$ of which are wild-born. Mink now occupy all the main waterways in Hiiumaa, including the stream flowing through the town of Kärdla (Figure 17.4). Tentatively, we suggest that the population could be described as 'established' although it is perhaps not yet of sufficient size to be self-sustaining.

On the Continent, the size and geographical extent of remnant European mink populations is uncertain,

(a)

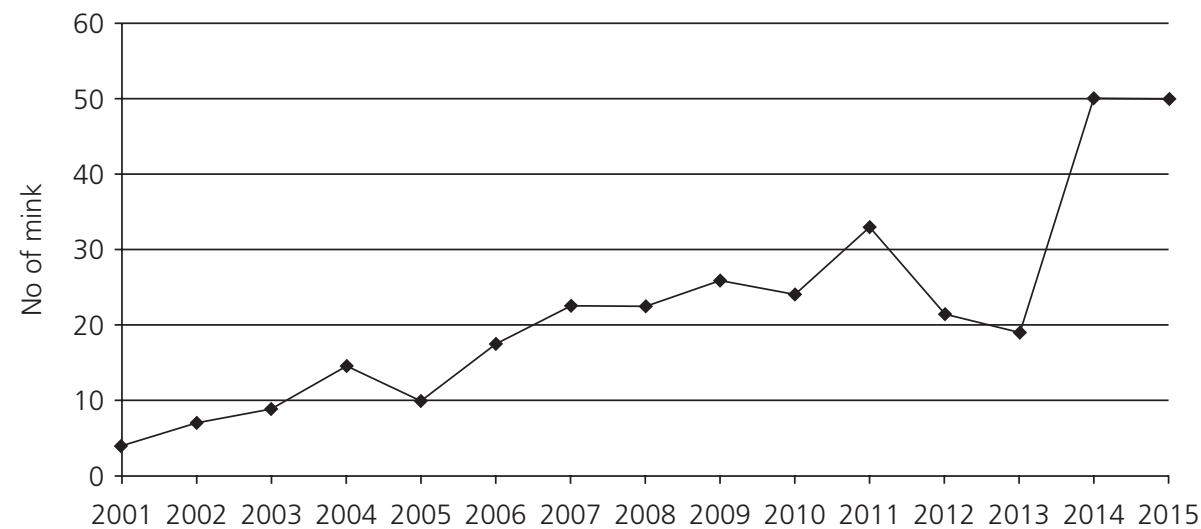

(b)

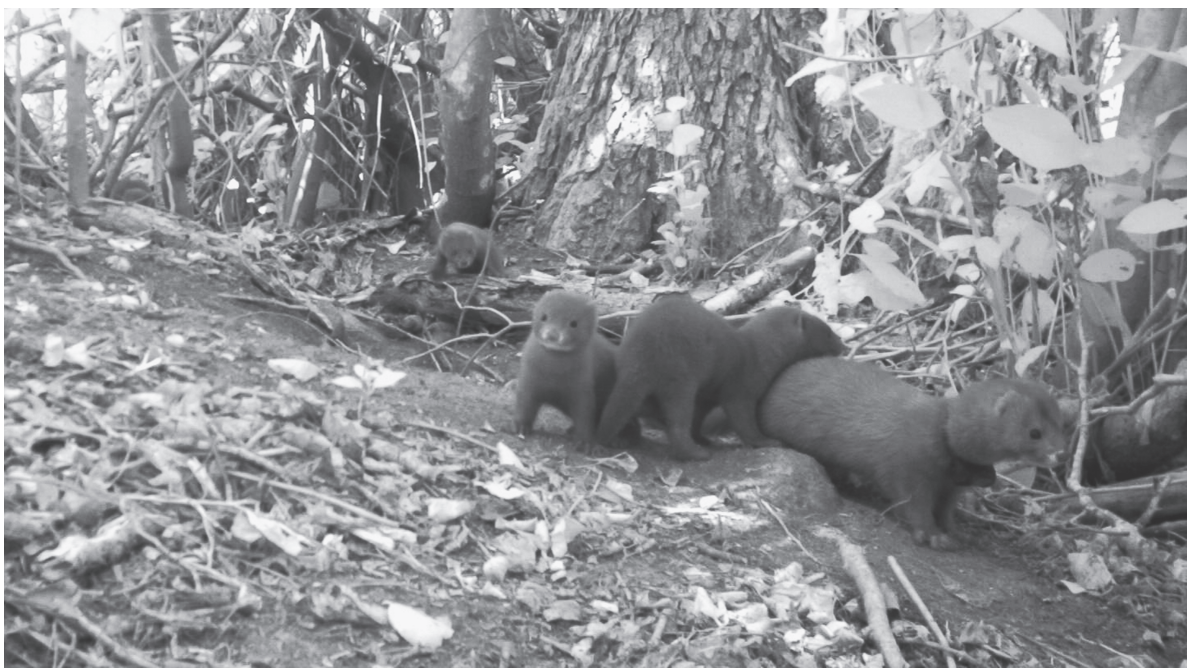

Figure 17.7 Monitoring mink numbers on Hiiumaa island, Estonia. a) Population size, estimated on the basis of live trapping and ad hoc information from local people (numbers released each year are given in Table 17.1); b) camera-trap photo showing a wild-born litter of four, 2014. 


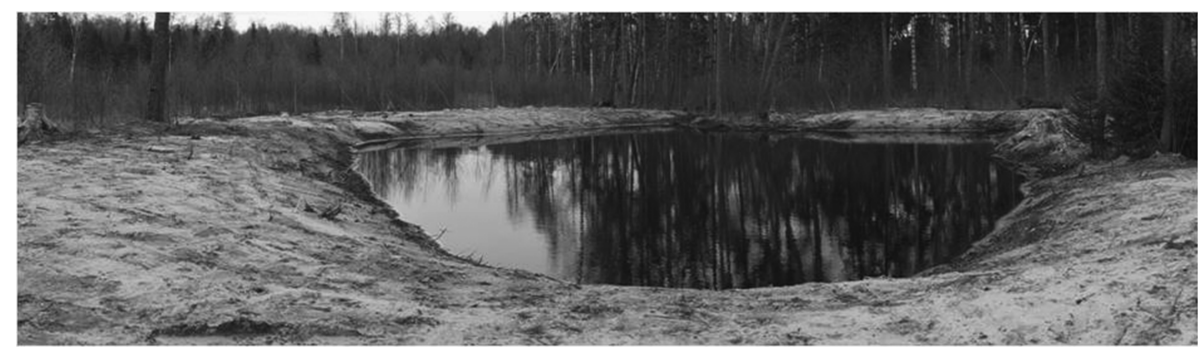

Figure 17.8 An artificial pond on Hiiumaa island, Estonia. Due to high levels of land reclamation activities on the island in the past, spawning ponds tend to dry out in summer before amphibians have dispersed, and abundance of amphibians is four times lower on the island than on the mainland. Artificial ponds are excavated in hydrologically impoverished forests to support the main prey of the mink: brown frogs Rana temporaria and $R$. arvalis. Comparison of artificial with natural ponds revealed relatively high densities of amphibians in artificial ponds but also higher diversity and abundance of macroinvertebrates, including two Odonata species of conservation concern: the green hawker dragonfly (Aeshna viridis) and the sedgling or pygmy damselfly (Nehalennia speciosa), that were otherwise uncommon in the managed forests in the study area (Remm et al. 2015). (C) T. Maran.

partly because of their dynamic nature: almost all persist perilously close to invading American mink, and all are thought to be declining (Maran et al. 2016b). In 2014, two of us (TM and MP) participated in a preliminary survey of mink in the Danube delta in Romania. There, the habitat appears good, prey availability is high, and American mink appear to be absent. The size of the European mink population was estimated to be in the region of 1000 to 1500 but more thorough systematic surveys are needed to refine this estimate. In any case, the Romanian population appears to be the largest European mink population in the world, and is thus of utmost importance for the global conservation of the species (Maran et al. 2016b). The only other population in Europe that might still be considered viable is the Spanish population, although the increasing American mink population there means that sustainability, even in the relatively short term, is questionable.

\section{European mink in Spain}

In 2000/2001, European mink occurred in the Basque country, Navarre, La Rioja, and eastern Castile and León (Palazón et al. 2002), covering an area of 22,500 $\mathrm{km}^{2}$ containing c. $2000 \mathrm{~km}$ of river (five times the extent of waterway in Hiiumaa), at densities estimated to be between 0.25 and 1.25 mink per km of river (Palazón et al. 2002). Road kill and trapping data prior to the 1970s suggest that European mink may have originally been present as far west as Cantabria (Zabala et al. 2004) and a single record in the River Ebro delta in Catalonia (Ruiz-Olmo and Palazón 1990) has been speculated to be a long-distance disperser to the southeast-neither have been confirmed, however, and the current known distribution is considerably more restricted (Figure 17.9a). At the time of writing, European mink appear to be largely restricted to Navarre and La Rioja (having disappeared from much of the Basque country due to the effects of habitat fragmentation and the invasion there of American mink, Põdra et al. 2013b, Figure 17.9b); low numbers are also present in eastern Castile and León and in Aragon (Gómez et al. 2011; Balmori et al. 2015). European mink were first trapped in Aragon in 2007, suggesting that they are ranging further east and southeast in the Iberian peninsula (Gómez et al. 2011). The largest population occurs along a $250 \mathrm{~km}$ stretch of the upper Ebro river and its tributaries (Palazón and Melero 2014, Figure 17.9c) but there are no robust estimates of total population size in Spain: the best 'guesstimate' is about 500 individuals (Palazón and Melero 2014), but this is based on a mix of information and data collated prior to 2006 and may, in reality, be much lower.

There are a multitude of threats that present a risk to the Spanish European mink population, the most significant of which is the presence of the American mink. The first mink fur farms in Spain were established in the late 1950s, and American mink were first recorded in the wild in the late 1970s in central Spain (Delibes and Amores 1978). American mink are believed to have spread from six distinct nuclei (established between the mid-1980s and the early 1990s), associated (in at least three cases) with massive escapes from farms facilitated by accidental damage to cages and fences caused by, for example, fire or extreme weather (Ruiz-Olmo et al. 1997). The Spanish range of the American mink 
(a)

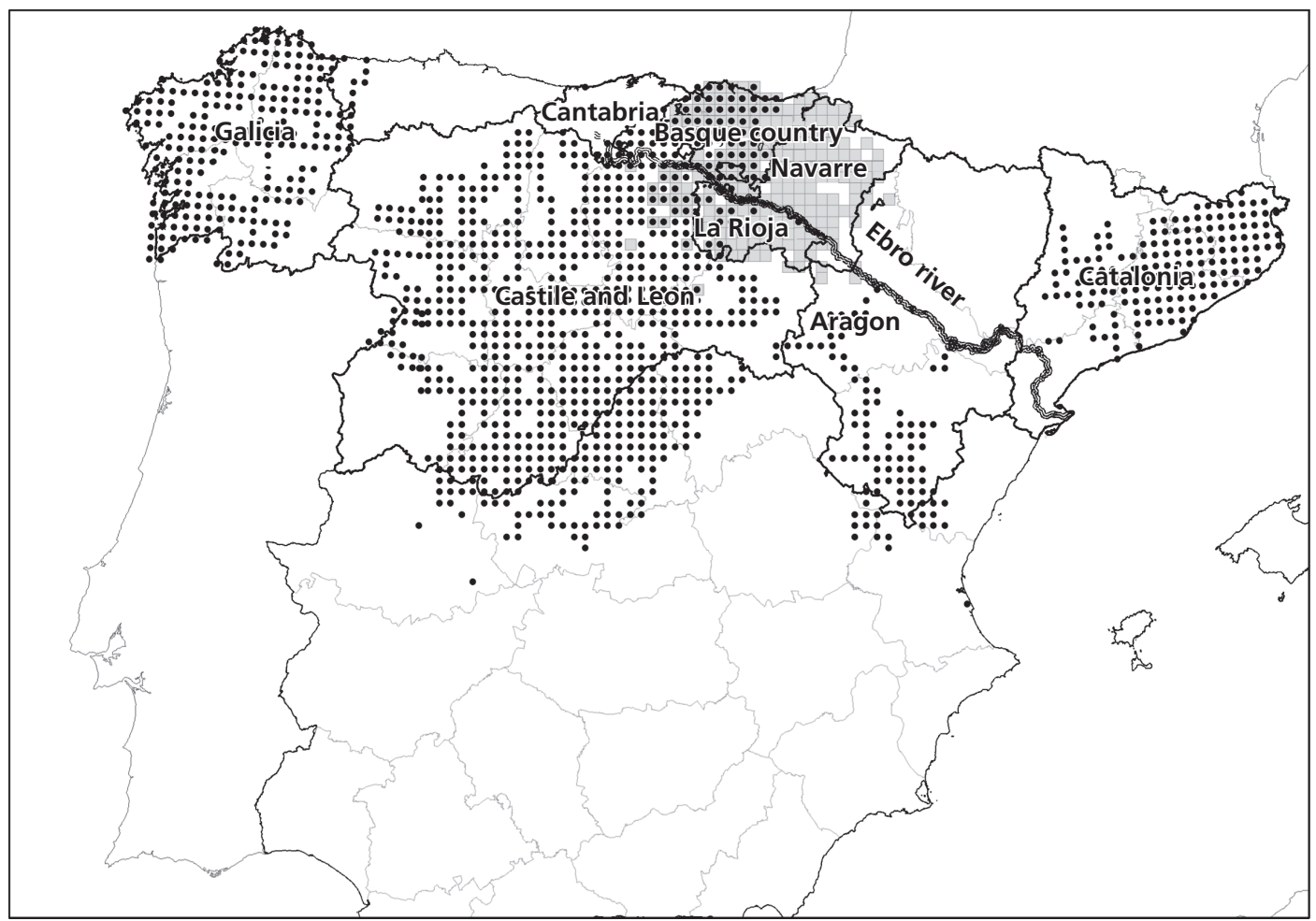

(b)

(c)
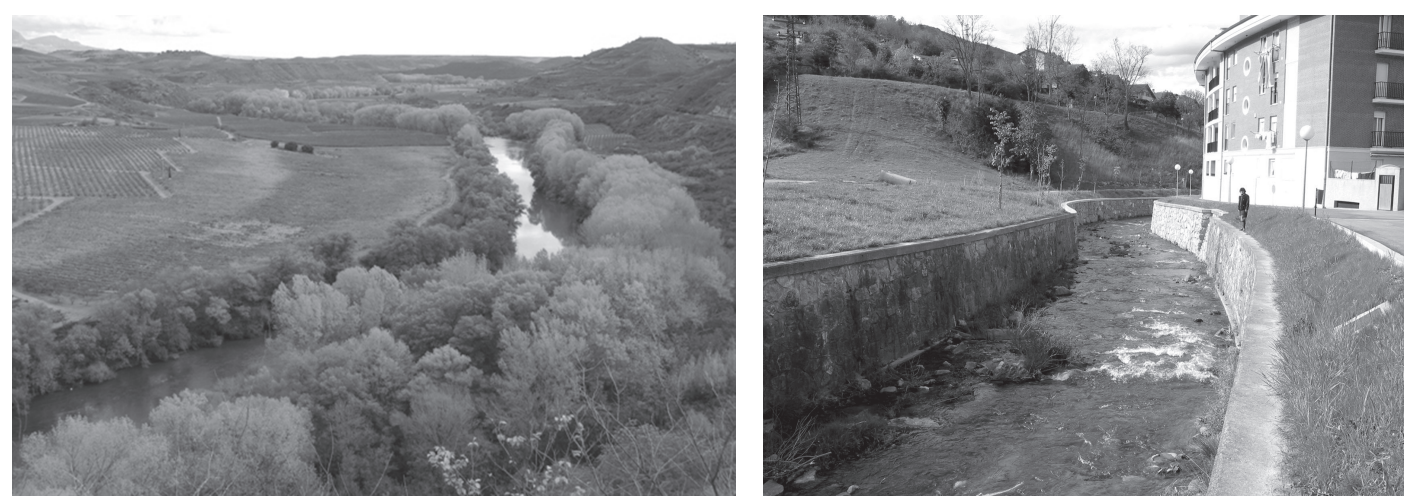

Figure 17.9 a) Distribution of European (grey blocks) and American (black dots) mink in Spain, 2012 (reproduced from Põdra and Gómez, submitted), b) R. Ebro, where the largest Spanish mink population is currently found. (C) Madis Põdra, and c) R. Oria, Basque country. Concrete river banks such as those shown here present barriers to European mink movement and result in fragmented and degraded habitat. (C) Jorge GonzálesEsteban. 
now essentially surrounds the existing European mink range (MAGRAMA 2014, Figure 17.9a) and the area occupied is continually expanding while that occupied by European mink is contracting. In 2011, American mink appeared to be spreading in the lower Ebro river (the same river that provides a stronghold for the European mink in its upper reaches, Gómez, pers. comm., Figure 17.9c). Tracking the co-occurence of the two species across their Spanish range over 11 years (2000-2011), Santulli Sanzo et al. (2014) found that the loss of European mink from a site was almost twice as high when it co-occurred with American mink than in its absence, and that over the 11-year monitoring period, European mink became extinct at more sites than they colonized. They concluded that the overall range contraction of the European mink in Spain was due to competitive exclusion by invading American mink.

A number of regional attempts to control American mink has been underway since the late 1990s and early 2000s. More than 4000 American mink have been captured thus far (up to 2012), mostly from Castile and León and Catalonia, but also in the Basque country, La Rioja, and in Aragon (MAGRAMA 2014). Comparing the relative abundance of American mink in four culled populations in Catalonia with a non-culled population revealed, however, that while trapping may reduce relative abundance, eradication was not achieved, and there was little indication (over the fouryear study) of a decline in population growth rates (Melero et al. 2010). Mañas et al. (2016a) also show that the impact of culling has been negligible for three populations subject to different trapping efforts between 2002 and 2008, and across Spain, Santulli Sanzo et al.'s (2014) analysis of range-wide American mink occupancy detected short-term local impacts of culling but no evidence of effectiveness at a larger scale.

Other potential risks include habitat degradation and pollution, disease (particularly ADV, which may be spread by American mink and has very high prevalence in Spain, Mañas et al. 2016b; see also Newman and Byrne, Chapter 9, this volume), road traffic accidents, and inbreeding (Palazón and Melero 2014), but all pale into insignificance compared to the American mink. Nevertheless, road-kills can be high, particularly for males during the mating season (Palazón et al. 2012), and 'barriers', such as concrete or rubble river banks and drainage pipes, on rivers and streams reduce habitat available for mink (Zuberogoitia et al. 2013, Figure 17.9c). Furthermore, these two factors interact such that, although mink can pass these artificial structures to move up and down 'fragmented' rivers, they are at increased risk of predation and road accidents when they do so (Zuberogoitia et al. 2013). Both habitat fragmentation and road-kills might have a negative impact on European mink at a local level.

In 2004, a small captive breeding programme was initiated in Spain, based on 10 founders captured in 2004 and 2005. Between 2005 and 2012, 108 mink (in 30 litters) were born, and there are currently about 50 breeding mink in captivity in Spain held in ten centres; since 2012, a further four new founder males have been added to the population. Given the urgency of the situation, and the rapid documented disappearance of wild European mink in Spain, a small number of these captive-bred individuals was released into the wild to evaluate the possibility that population reinforcement might increase the chances of European mink persistence where American mink occurred at very low densities. Between 2008 and 2010, 27 (nine male, 18 female) European mink were released in a 200 ha wetland in the Basque country in northern Spain, where European mink had previously (up to 2001-2002) been common. For seven years prior to the release, American mink in the region had been trapped and culled but not totally eradicated; the density of American mink remaining at the time of the release was not quantified but was deemed to be low based on captures of less than five individuals over $150 \mathrm{~km}$ of river during the release (compared with $>65$ in the second and third years of the initial culling period, Põdra et al. 2013b). European mink were tracked for five months after release to evaluate their adaptation to the wild: only five (18.5\%) were confirmed to have survived the entire period (Põdra et al. 2013b). Most $(76 \%, \mathrm{n}=16)$ were killed, and measurement of bite marks (compared with the inter-canine distances of small carnivores, combined with other field signs such as the presence of tracks and whether the carcass was located in the water or on land) revealed that almost half of those ( $44 \%$ of predation events, $\mathrm{n}=7$, including two females and five males) were killed by another 'mink-sized' carnivore. Põdra et al. (2013b) inferred that these 'mink-sized' carnivores (in at least six of seven cases) were most likely male American mink (largely because the carcasses were found in the water or near mink tracks, and because ongoing trapping suggested that male American mink were relatively more abundant than other small carnivores, such as genets and polecats). Other predators were foxes or dogs $(n=6)$ and raptors $(n=3)$. None of the mink that were killed were eaten.

The results were clear: even low numbers of American mink are likely to be prohibitive to future 
restoration efforts for European mink. Further releases are planned but outside the area occupied by American mink and in areas that are deemed defensible against future colonization.

\section{The origins and spread of European mink in Spain}

There is considerable confusion regarding the origins and the apparent contemporary spread of European mink in Spain (and indeed in France, where European mink apparently appeared in the nineteenth century, Youngman 1990). Published records of European mink in northern Spain suggest that they first appeared there in the early 1950s (presumably as dispersers from the established population in southwestern France) and, since that time, dated records suggest a gradual spread in their distribution to the south and southeast (Palazón and Ruiz-Olmo 1992; Palazón et al. 2003; Zabala et al. 2004; Gómez et al. 2011). That European mink simply went unnoticed in Spain prior to 1950 is deemed unlikely (Zabala and Zuberogoitia 2003; Zabala et al. 2004). Zabala et al. (2004) suggest that further spread over the last few decades may have been facilitated, at least in part, by a reduction in agriculture and the abandonment of rural areas, development of riverbank protection policies, and/or a reduction in the use of poisons, but what might have allowed the earlier spread into the region is not known. Debating the origins of the population might seem a rather rarefied issue, but it has serious conservation implications because the relatively recent arrival of the species in the Iberian peninsula has led some people to argue that European mink are non-native in Spain (Clavero 2014; see also Carbonell 2015), and thus should not be protected in recently occupied areas. However, the assertion by Clavero (2014) that European mink were most likely introduced by humans to France and Spain is based on an incomplete interpretation of genetic analyses by Michaux et al. $(2004,2005)$. European mink in France and Spain exhibit an almost complete lack of genetic variation (and comprise a single haplotype, that is closely related to those in eastern populations but not currently found there), suggesting that the current western population arose from a small number of founders (Michaux et al. 2004, 2005; Cabria et al. 2015). However, these authors give two, equally likely, possible explanations: an anthropogenic introduction of individuals from Central and/or Eastern Europe, or natural migration from Central Europe. Cabria et al. (2015; see also Lodé 1999) also suggests that there may have been a genetic bottleneck event in France at some time in the past. Certainly, low genetic diversity at range margins is consistent with range expansion (e.g. Excoffier et al. 2009; Hallatschek and Nelson 2009), and similar genetic patterns have been observed in fisher (Martes pennanti, Wisely et al. 2004) and stone marten (M. foina, Vergara et al. 2015) populations, albeit due to historical range expansions that occurred thousands of years ago.

Zabala et al. (2004) show how the distribution of the European mink has changed since 1700 (Figure 17.10), illustrating clearly the dynamic nature of the mink's western range boundary and showing how they could have spread from northeastern Europe over the last 300 years (see also Zuberogoitia et al. 2016). Shifting distributional ranges are not a new phenomenon; there are numerous examples of species expanding their range in response to altered ecological and/or environmental conditions across taxa. The spread of golden jackals (Canis aureus) within Europe provides a good parallel case. Prior to the sixteenth century, jackals in Europe were confined to the southeast of the continent (the coastal regions of Croatia, Greece, and Bulgaria), but through the twentieth century, and since, have steadily expanded their range to the north, such that they now occur in Austria, Ukraine, and most of the countries between, and have been seen in many northern European countries, such as Germany, and as far north as Estonia (Kowalczyk et al. 2015; Rutkowski et al. 2015). In a legal analysis of the implications of existing conservation legislation for jackals and other naturally expanding species, Trouwborst et al. (2015) conclude that international legal obligations mean that countries do not have the freedom to decide how to deal with a newly arriving species nor to define its range. European mink are strictly protected under the EU Habitats Directive (Council Directive 92/43/EEC on the conservation of natural habitats and of wild fauna and flora), across their 'natural range', an area defined as that to which the species could have 'spread on its own ...'. Where the mechanism of 'arrival' (i.e. human-assisted or not) in an area is ambiguous, 'member states must act in accordance with the precautionary principle, opting for the course of action that is most likely to secure the Directive's conservation objectives' (i.e. to ensure, or to achieve, favourable conservation status) (Trouwborst et al. 2015). The Spanish mink population is hugely important for the status of the species in Europe, and its protection and restoration are therefore a crucial aspect of the conservation of the species at an EU level (see also Díez-León et al. 2015, 


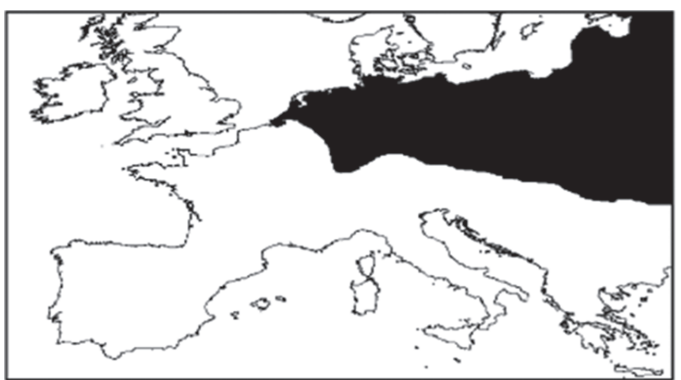

1700

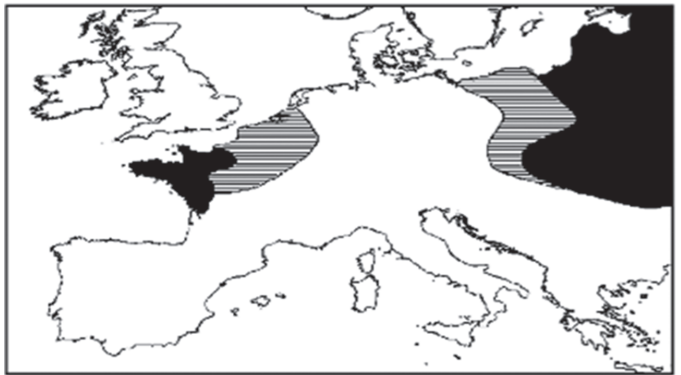

1900

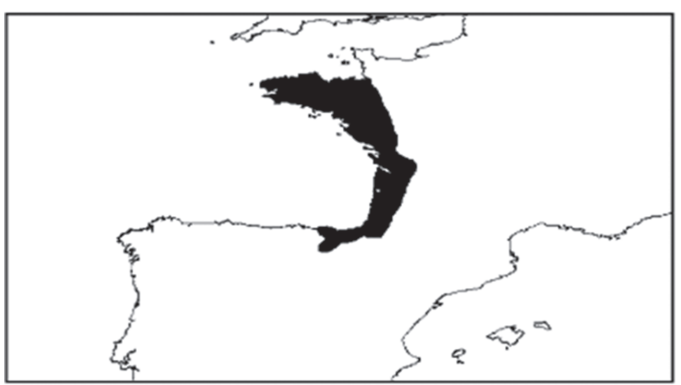

1975

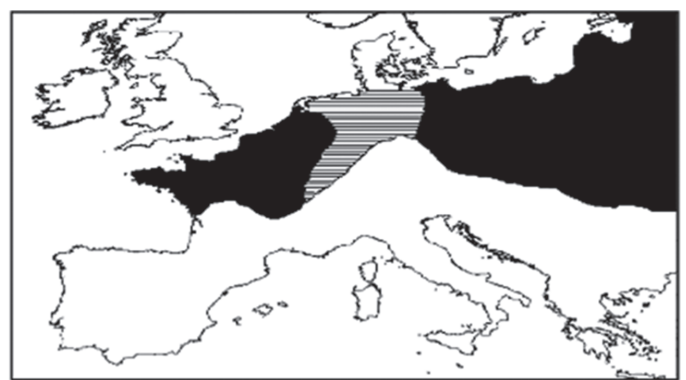

1850

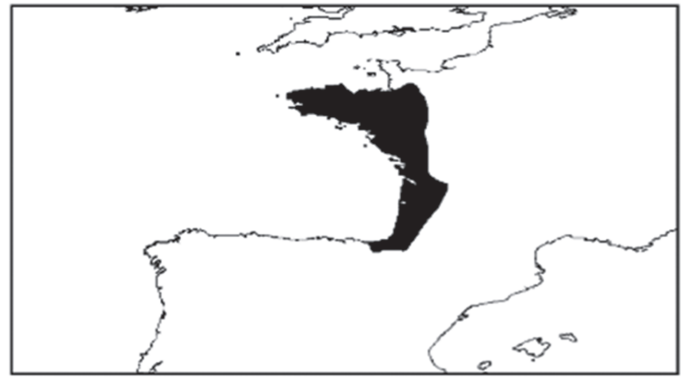

1950

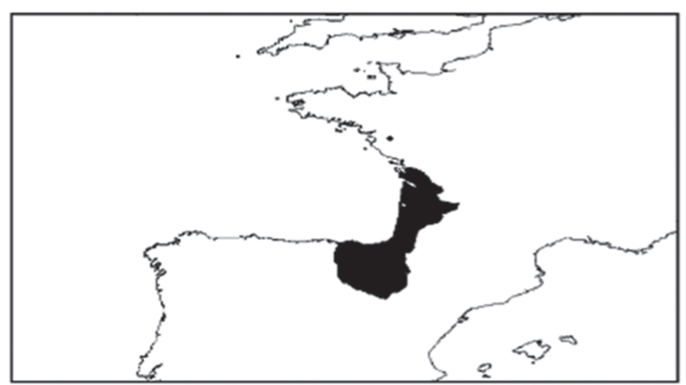

2000

Figure 17.10 Changes in the distribution of European mink between the eighteenth and the twenty-first centuries. Black areas indicate known European mink presence; shaded areas indicate where mink were recorded as rare or disappearing. Reproduced from Zabala and Zuberogoitia (2004).

and Zuberogoitia et al. 2016). Explicit consideration and allowance of continued range expansion, in this case, will be particularly important given the presence of American mink in many formerly occupied areas (see Figure 17.9).

\section{Personality types}

Of the myriad of factors that may influence post-release survival in reintroduction programmes (including, amongst others, habitat quality, release protocols, weather conditions at the time of release, density of potential predators and/or competitors, presence of disease, suitability of the animals released, and chance events), it is not always obvious which are most influential, and all may interact in complex ways. In practice, much of the work described in this chapter has focused on refining pre-release conditions to limit the potentially negative effects of being born in an artificial environment. Another factor that is of increasing academic interest in reintroduction projects is the existence, and influence of, individual behaviours or animal personalities (McDougall et al. 2006; Watters and Meehan 2007; Smith and Blumstein 2013). The practical relevance being whether it is possible to select (from captive-bred stock) individuals with the greatest 
chance of survival (e.g. Mathews et al. 2005). BremnerHarrison et al. (2004) found that shy swift foxes were more likely to survive the first six months post-release than were bold swift foxes but there have been no other tests of the effect of animal personality on postrelease survival of which we are aware.

European mink exhibit distinct personality traitsboldness, exploration, and sociability (and even kits may differ in boldness, Kiik et al. 2016) — but the expression of personality appears to be situation and context-specific (Haage et al. 2013). Captive males displayed heightened levels of boldness and exploration in the breeding season; females became less bold. And animals exhibited different behaviours in front of a mirror (simulating the presence of a conspecific) depending on whether they were in their own territory (enclosure) (in which case they were 'bold') or outside it (when they were 'sociable', Haage et al. 2013). Personality-tested, captive-bred individuals, radio-tracked for 60 days following release on Hiiumaa $(2013, \mathrm{n}=13)$ and on the neighbouring island of Saaremaa $(2012, \mathrm{n}=10)$, revealed that both boldness and exploration were correlated with survival. Bolder animals survived longer (within the 60-day monitoring period) (Figure 17.11a). But the effect of 'explorativeness' differed between years: individuals with a tendency to explore survived longer in 2013 (on Hiiumaa), but the opposite was true in 2012 (on Saaremaa) (Figure 17.11a). As in earlier releases on Hiiumaa and in Spain, the leading cause of death in both releases (overall $83 \%$ of total mortality) was predation, but predation rates, and the number of days survived, differed considerably between the two islands. In 2012 (on Saaremaa), none of the animals survived the 60day monitoring period; mean survival was 15 days and nine of the ten animals released died within 35 days of release (Figure 17.11b). In 2013 (on Hiiumaa), 73\% of the 15 animals released were still alive at the end of the 60-day monitoring period (Figure 17.11b). The variable exploration effects are difficult to explain-Haage et al. (2017) discuss the possible influence of weather (2012 was colder and wetter than 2013), and thus of prey availability, and perhaps different personality types having different coping strategies. Differences between the islands in densities of competing predators may also have had an effect on the risk associated with exploration, but since Saaremaa has high densities of red foxes and Hiiumaa high densities of pine martens, the precise nature of any such effect is hard to assess (Haage et al. 2017; we do not know whether pine martens kill European mink or not, but being slightly larger than American mink, see Macdonald et al., Chapter 1, this volume, presumably they could). Unlike the previous releases in Hiiumaa and Spain, Haage et al. (2017) did not detect a difference in survival between the sexes but since males are generally bolder and more exploratory than females, they suggest that earlier apparent sex effects were perhaps, in reality, the result of personality differences.

The possibility of using these findings as a conservation tool is exciting; however, there are a number of questions (both theoretical and practical) that require answers before operational recommendations can be made and further work in this area is required.

\section{Where do we go from here?}

Despite considerable effort across several countries to protect or to restore European mink populations, the picture remains bleak. Looking to the future, increased awareness, large-scale coordinated efforts, and strategic planning is needed at local, regional, national, and international levels. One immediate priority is to assess the size and status of the Romanian population. Within the EU, efficient management requires development of an EU action plan, backed by sufficient and continued resources.

Conservation actions come under four constituent parts: captive breeding, reintroduction, habitat protection and improvement, and American mink control.

Current country-level captive breeding efforts are insufficient and need to be coordinated across Europe (Maran et al. 2016b). Decisions are needed on how to treat low-diversity western and high-diversity eastern populations (see Michaux et al. 2005). Research questions include how to increase the number of males successfully breeding, and whether experience with live prey is necessary or beneficial.

It is not clear why, or under what particular circumstances, captive-bred animals are vulnerable to predation in the wild, and it is likely that the inter-relationships between individuals and their environment are so complex (particularly when that environment changes abruptly) that there is no simple prescription. Personality may be important, but is technically difficult to measure (see Haage et al. 2013 for details), and because different traits may be important for different situations (i.e. individuals that do well in a predatoravoidance context might do less well in competitive situations, and vice versa, Sih et al. 2004; Smith and Blumstein 2008) there may be no such thing as an 'optimal' personality type. 
(a)
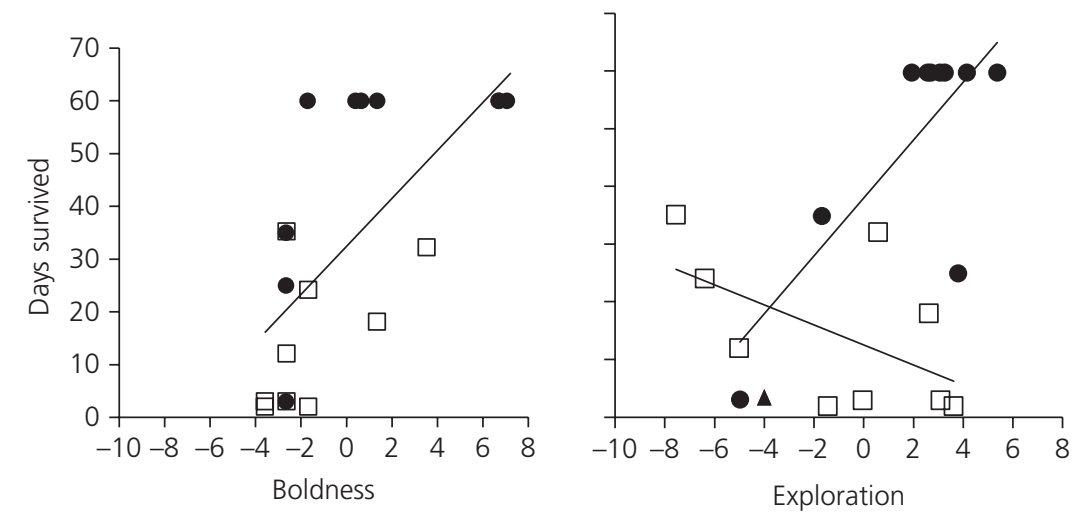

(b)

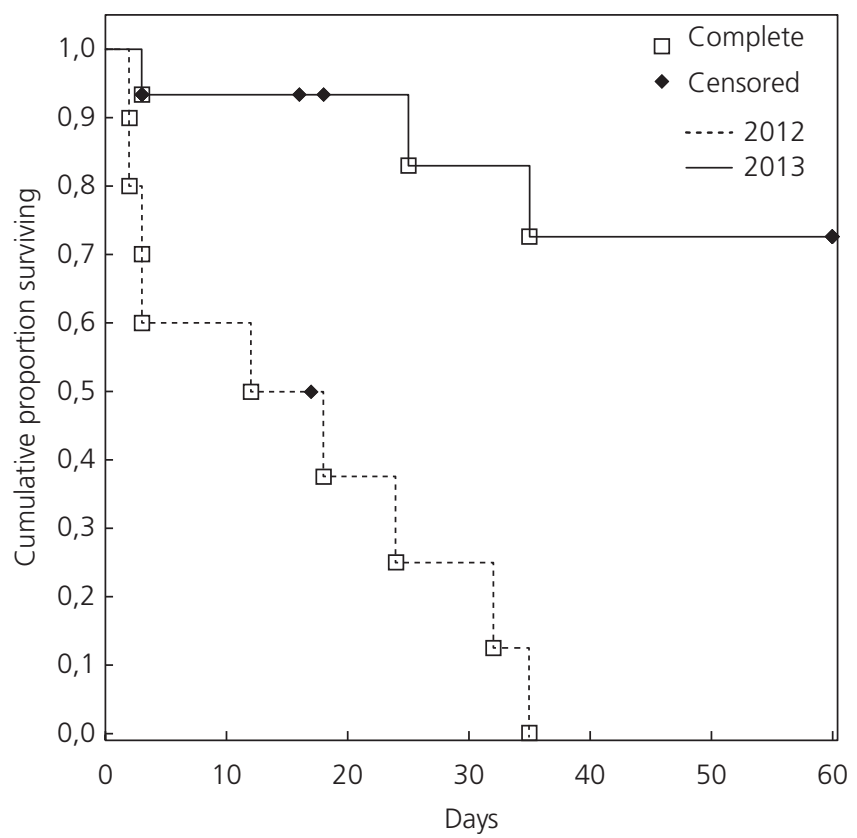

Figure 17.11 a) Relationship between personality traits ('boldness' and 'exploration') and survival of released European mink on the Estonian islands Saaremaa in 2012 (open squares) and Hiiumaa in 2013 (filled circles). Personality was measured pre-release in captivity and post-release survival by radio-tracking. Trend lines indicate statistically significant effects. The filled triangle marks an individual believed (but not confirmed) to have died; this animal was excluded from statistical analysis. b) Survival analysis for all individuals combined on the two islands, Saaremaa (2012) and Hiiumaa (2013). There was no survival beyond 35 days on Saaremaa and seven cases of survival throughout the full 60-day period of radiotracking on Hiiumaa. Reproduced from Haage et al. (2017).

Protected areas are needed to secure large areas of suitable habitat, and whilst the presence of humans is not problematic per se, roads, barriers, and pollution are. Innovative restoration schemes might benefit mink (and freshwater biodiversity in general). And, because of the presence of American mink, currently occupied sites may not represent the best habitat, or offer the best longterm solution for European mink, so areas beyond the current range of European mink need to be considered.

Above all, American mink need to be removed from European mink-occupied areas, and further expansion of American mink range prevented. Displacement of 
European mink by American mink is inevitable unless ongoing management efforts are improved. Trapping needs to be prioritized and targeted for maximum efficiency. For example, targeting the edge of the current American mink range might prevent further expansion (Melero et al. 2010) and centring trapping on the Ebro river valley might allow further expansion of European mink range. Using effective trapping methods, developed and tested in the UK, local level eradication can be possible (and this has been demonstrated over a large area in Scotland, see Fraser et al., Chapter 16, this volume). In the future, maintaining areas cleared of American mink free of immigrants from neighbouring regions or countries will be key.

Crucially, the source of American mink has to be eliminated. Is it possible to ensure that mink fur farms are escape-proof? Is it appropriate to locate them anywhere near the last remaining range of the European mink? Difficult questions that go beyond the realms of conservation biology, as the future of European mink depends ever more precariously on the political will to avert their extinction.

\section{Acknowledgements}

This work has been supported by the following organizations, to which we are extremely grateful: the Darwin Initiative, EU LIFE (Project No. LIFE2000NAT/EE/7081), the EAZA Carnivore Campaign, Estonian Environmental Board, Estonian Environmental Investment Centre, Zoos Help Foundation, Rotterdam Zoo, Helsinki Zoo, Zoological Society for Conservation of Species and Populations, Stiftung der Artenschutz, Denver Zoological Society, Thoiry Zoological Park, GaiaPark, Bernhandine Foundation, Tallinn Zoo, and by the personnel of the Spanish Environmental Ministry, Tragsatec, Regional Governments of La Rioja, Navarre, Castile and León, Aragón, and the Basque country, and the European Mink Association. Personally we would like to thank Mirenka Ferrer, Santiago Palazón, Sisco Mañas, and Asun Gómez. Thanks also to Chris Newman and David Macdonald for comments on an earlier draft, and to Marianne Haage for providing personality data. 